\title{
A system to simultaneously detect tick-borne pathogens based on the variability of the $16 \mathrm{~S}$ ribosomal genes
}

\author{
Jana Melničáková1, Marketa Derdáková2,3 and Imrich Barák ${ }^{1 *}$
}

\begin{abstract}
Background: DNA microarrays can be used to quickly and sensitively identify several different pathogens in one step. Our previously developed DNA microarray, based on the detection of variable regions in the 16S rDNA gene (rrs), which are specific for each selected bacterial genus, allowed the concurrent detection of Borrelia spp., Anaplasma spp., Francisella spp., Rickettsia spp. and Coxiella spp.

Methods: In this study, we developed a comprehensive detection system consisting of a second generation DNA microarray and quantitative PCRs. New oligonucleotide capture probes specific for Borrelia burgdorferi s.l. genospecies and Candidatus Neoehrlichia mikurensis were included. This new DNA microarray system required substantial changes in solution composition, hybridization conditions and post-hybridization washes.

Results: This second generation chip displayed high specificity and sensitivity. The specificity of the capture probes was tested by hybridizing the DNA microarrays with Cy5-labeled, PCR-generated amplicons encoding the rrs genes of both target and non-target bacteria. The detection limit was determined to be $10^{3}$ genome copies, which corresponds to 1-2 pg of DNA. A given sample was evaluated as positive if its mean fluorescence was at least 10\% of the mean fluorescence of a positive control. Those samples with fluorescence close to the threshold were further analyzed using quantitative PCRs, developed to identify Francisella spp., Rickettsia spp. and Coxiella spp. Like the DNA microarray, the qPCRs were based on the genus specific variable regions of the rrs gene. No unspecific cross-reactions were detected. The detection limit for Francisella spp. was determined to be only 1 genome copy, for Coxiella spp. 10 copies, and for Rickettsia spp., 100 copies.

Conclusions: Our detection system offers a rapid method for the comprehensive identification of tick-borne bacteria, which is applicable to clinical samples. It can also be used to identify both pathogenic and endosymbiontic bacteria in ticks for eco-epidemiological studies, tick laboratory colony testing, and many other applications.
\end{abstract}

Keywords: Tick-borne bacteria, DNA microarray, Quantitative PCR

\section{Background}

Tick transmitted diseases are a serious and permanent public health problem. In Europe, the most frequent and most epidemiologically important vector is the hard tick Ixodes ricinus. It transmits viral, bacterial and protozoan agents to humans and animals. The most common and important tick-transmitted disease in the northern hemisphere, Lyme borreliosis, is caused by spirochetes from

\footnotetext{
* Correspondence: imrich.barak@savba.sk

'Institute of Molecular Biology, Slovak Academy of Sciences, Dúbravska cesta 21, 845 51, Bratislava, Slovak Republic

Full list of author information is available at the end of the article
}

the Borrelia burgdorferi sensu lato (s.l.) complex. It currently includes 19 different genospecies [1]. The considerable genotypic and phenotypic heterogeneity of the $B$. burgdorferi s.l. complex has been linked to differences in pathogenicity, clinical symptoms and ecology [2-4]. The Borrelia genus also includes a second group of spirochetes, called the relapsing fever group. The spirochetes of this group are transmitted mainly by soft ticks, but can also utilize some hard ticks as vectors [5].

Anaplasmoses are also common tick-borne, zoonotic bacterial diseases. The causative agents are intracellular gramnegative bacteria that belong to the family Anaplasmataceae
C Biomed Central

(c) 2013 Melničáková et al.; licensee BioMed Central Ltd. This is an Open Access article distributed under the terms of the Creative Commons Attribution License (http://creativecommons.org/licenses/by/2.0), which permits unrestricted use, distribution, and reproduction in any medium, provided the original work is properly cited. 
[6]. The genus Anaplasma consists of Anaplasma marginale, Anaplasma ovis, Anaplasma bovis and Anaplasma platys. While they are primary of veterinary significance, A. phagocytophilum can cause granulocytic anaplasmosis in humans as well as horses and dogs and tick-borne fever in ruminants [7]. A relatively new member of the family Anaplasmataceae is Candidatus Neoehrlichia mikurensis [8]. It infects endothelial cells and most infection symptoms depend on the physical status of the patient. The illness predominantly develops in immunocompromised patients [9-12].

Less common bacteria that may be transmitted by Ixodes ricinus amongst other tick species include Francisella spp. and Coxiella spp. Coxiella burnetii is the causative agent of Q-fever, which can be either an acute or chronic disease. Francisella tularensis causes tularemia, a febrile disease with myalgia and headache and when left untreated, it can cause a high mortality rate [13]. Most cases of disease caused by both $C$. burnetii and $F$. tularensis result from non-vector transmission.

Another European tick-borne obligate intracellular parasite, which is also globally distributed, is Rickettsia spp. The genus Rickettsia contains many species which form several biogroups, including the typhus fever group, the spotted fever group and the group causing tick-borne lymphadenopathy or Dermacentor spp. borne necrosis - erythema - lymphadenopathy (TIBOLA or DEBONEL) [14]. Many other Rickettsia species have been recently identified, but are not yet well described, including the human pathogens $R$. helvetica and $R$. aeschlimannii $[15,16]$.

Considering all the serious diseases that humans can potentially be exposed to after a tick-bite, an unambiguous diagnostic tool is essential for identifying them. The most reliable modern diagnostic tools employ serological tests, including ELISA (enzyme linked immunoabsorbent assay), Western blot, indirect immunofluorescence assay (IFA), a microagglutination test, and in the case of rickettsial infection, the Weil-Felix test [17]. Unfortunately, these methods are only indirect and do not allow illnesses to be diagnosed in the early stages of infection. Another major limitation of serology is cross-reactivity [18], application of the non-standardized antigen preparations and discrepancies in test procedures among laboratories can lead to different test results. Furthermore, identification of Candidatus N. mikurensis using serology is presently not possible and A. phagocytophilum and $E$. chaffeensis antigens do not interact with Candidatus N. mikurensis antibodies [19]. The primary approach for detecting Candidatus N. mikurensis therefore relies on PCR-based methods.

Molecular biology approaches offer the advantages of directly detecting these pathogens during early infection along with better taxonomic classification. The most common techniques employ conventional, nested, or quantitative PCR (qPCR) targeted to a genus or species specific gene, such as $16 \mathrm{~S}$ rDNA gene (rrs), gltA, omp, ospA or $\operatorname{ssp} C$ [20-23]. Another method, commonly used for identifying $B$. burgdorferi s.l., targets the 5S-23S rDNA $(r r f A-r r l B)$ intergenic spacer followed by genotyping using RFLP or SSCP [24,25]. These tests target the rDNA genes because they are minimally affected by horizontal gene transfer. Typically, these genes have hypervariable regions, specific for each bacterial genus, which are flanked by conserved regions [26].

The more recent, microarray-based techniques are high-throughput large-scale screening systems for the simultaneous identification of several target amplicons. DNA microarrays are used in many fields of research, including transcription profile analysis and DNA-DNA or protein-protein interactions. Microarrays have been developed for the identification of microorganisms in soil extracts [27], for the detection of multiple pathogens [28-30] and for differentiating between different Borrelia genospecies [31]. These techniques employ DNA or RNA as a template for the preparation of a target product which is suitable for passive hybridization with complementary DNA fragments or oligonucleotides bound to the surface of a slide. The stringency and hybridization efficiency is regulated by solution composition and temperature.

An alternative to the DNA microarray is an electronic microarray - biosensor, which can be prepared using standard complementary metal oxide semiconductor (CMOS) technology. This "smart" biosensor uses an electric field to regulate the stringency, transport and active hybridization of nucleic acids [32,33]. An electronic microarray based on the genus-specific variability of the rrs gene has already been developed for the detection of marine bacterial species [34].

In this study, we report the development of a detection system combining a second generation DNA microarray with qPCR for the detection of pathogens in vectors or in clinical samples. A second generation DNA microarray is basically an epoxy glass slide with bound capture oligonucleotides, which code for the hypervariable regions of the rrs gene, specific for each bacterial genus. The target DNA is amplified, Cy5-labeled using nested PCR and passively hybridized with capture probes on the microarray. We also developed qPCRs employing the genus-specific, hypervariable regions of rrs for Coxiella spp., Francisella spp. and Rickettsia spp. to confirm the DNA microarray results.

\section{Methods}

Bacterial isolates and genomic DNA preparation

A DNA microarray was designed to detect bacteria from Borrelia spp., Anaplasma spp., Francisella spp., Rickettsia 
spp., Coxiella spp. and Candidatus N. mikurensis. The DNA of $A$. phagocytophilum, $R$. africae, $R$. slovaca, $F$. tularensis subsp. holarctica and C. burnetii Nine Mile phase II were from laboratory stocks [28]. The DNA from different Borrelia species and Candidatus N. mikurensis was isolated from questing ticks collected in Slovakia using the Qiagen DNeasy Blood and Tissue kit (Qiagen, Hilden Germany). Positive samples were identified using previously described PCR methods and sequenced $[19,25]$. Borrelial DNA was also isolated from cultures kindly supplied by Dr. Ian Livey (Baxter, Orth, Austria). DNA samples from non-targeted bacteria used as negative hybridization controls [28] were also taken from laboratory stocks.

\section{Sequence selection of capture probes}

The sequences of the DNA microarray capture probes $\mathrm{Bv}, \mathrm{Be}, \mathrm{Bg} 1$ used for the detection of Borrelia spp, C1 and $\mathrm{Cv}$ for detection of Coxiella spp., Av and A3 for detection of Anaplasma spp., F1v, F2v, Fa and F2 for detection of Francisella spp. and R1, Rv and Re for detection of Rickettsia spp. were previously published in Blaškovič and Barák [28]. New probes for detecting the DNA of Borrelia spp. and Candidatus N. mikurensis were designed (Table 1). The sequences for the new capture probes were chosen based on the hypervariable regions of the 16S rDNA genes ( $r r s)$. These were identified by an alignment of $16 \mathrm{~S}$ rDNA (rrs) sequences from GenBank and the Ribosomal Database Project II (RDPII) [35]. The sequences of the new capture probes were tested based on melting temperature and secondary structure prediction by Integrated DNA Technologies' OligoAnalyzer 3.1 online software [36]. The hybridization specificity of the designed probes was also analyzed using a Blast search [37].

For qPCR, three genus-specific oligonucleotides and dual-labeled probe sets were designed. The first set bound exclusively to the Coxiella spp. $16 \mathrm{~S}$ rDNA gene (rrs), the second set was specific for the Rickettsia spp. 16S rDNA gene (rrs), and the last set was designed to bind the Francisella spp. 16S rDNA gene (rrs). The unique region of the Coxiella spp. 16S rDNA gene (rrs) was identified by aligning the 16S rDNA (rrs) sequences and comparing them to the previously published primers and probes for the 16S rDNA gene (rrs) of Coxiella burnetii [22]. This region was used to design oligonucleotides and dual-labeled probes using GenScript (GenScript USA Inc., Piscataway, NJ, USA). The same strategy was used to generate oligonucleotides and dual-labeled probes for the Francisella spp. and Rickettsia spp. [39,40]. Like the DNA microarray capture probes, the qPCR probes and oligonucleotides were validated based on melting temperature, predicted secondary structure folding and hybridization specificity as described above.

\section{PCR amplification}

The sequences of all oligonucleotides and the probes used in this study are listed in Table 1.

\section{PCR amplification for DNA microarray}

The 16S rDNA (rrs) target genes of the targeted bacteria were amplified by nested PCR. The first cycle used $3 \mu \mathrm{l}$ of genomic DNA, 1× high yield buffer complete with 2 $\mathrm{mM} \mathrm{MgCl}_{2}$ (Jena Bioscience, Germany), $200 \mu \mathrm{M}$ of each dNTP, $1 \mu \mathrm{M}$ of 16S27f (forward) and 16S1495r (reverse) primers (Table 1) and 1U Taq Pol (Jena Bioscience, Germany). The primers 16 S27f and 16 S1495r are slightly modified fD1 and rP2 general eubacterial primers [38]. The second cycle was used to incorporate the fluorescent labeled Cy5-dUTP into the PCR product of the first amplification. The incorporation was performed as recommended by the manufacturer. Thus, the total $20 \mu \mathrm{l}$ reaction volume contained $1 \times$ high yield buffer complete with $2 \mathrm{mM} \mathrm{MgCl}_{2}$ (Jena Bioscience, Germany), $100 \mu \mathrm{M}$ of dATP, dCTP, dGTP, $50 \mu \mathrm{M}$ of dTTP, $50 \mu \mathrm{M}$ Cy5-dUTP (Jena Bioscience, Germany), $0.5 \mu \mathrm{M}$ 16S27f and 16S1495r primers (Table 1) and 1U Taq Pol (Jena Bioscience, Germany). $1 \mu \mathrm{l}$ of the PCR product from the first cycle was used as the template for the second cycle. The cycling conditions in both PCRs were the same. The initial denaturation was performed for 2 minutes at $94^{\circ} \mathrm{C}$ followed by 30 cycles of $94^{\circ} \mathrm{C}$ for 30 seconds, $52^{\circ} \mathrm{C}$ for 30 seconds, $72^{\circ} \mathrm{C}$ for 1 minute and 30 seconds. The program ended with final elongation at $72^{\circ} \mathrm{C}$ for 5 minutes.

\section{PCR amplification for quantitative PCRs ( $q P C R s$ )}

TaqMan probes for qPCRs were synthetized by Microsynth AG, Austria. The CbPr probe was covalently bound at the 5 'end with a FAM fluorophore and at the 3 'end with a TAMRA quencher; the RLOqPCRPr probe was covalently bound at the $5^{\prime}$ end with a HEX fluorophore and at the 3' end with a TAMRA; and the FrqPCRPr probe was covalently bound with Cy5 at the 5' end and BHQ-2 at the 3' end. The cycling conditions for all qPCRs were the same. The initial denaturation was performed for 2 minutes at $95^{\circ} \mathrm{C}$, followed by 40 cycles at $95^{\circ} \mathrm{C}$ for 25 seconds and $50^{\circ} \mathrm{C}$ for 1 minute. The reaction mixture consisted of $300 \mathrm{nM}$ of forward and reverse primes, $200 \mathrm{nM}$ dual-labeled probes, $1 \times$ TaqMan Master Mix (Bioron, Germany), $4 \mathrm{mM}$ $\mathrm{MgCl}_{2}$ and $5 \mu$ of template DNA.

\section{DNA microarray preparation and scanning}

Epoxy coated slides were used for DNA microarray prefabrication. The procedure was performed as recommended by the manufacturer (Corning Incorporated, USA). Briefly, the microarray capture probes were diluted in a printing solution, consisting of $150 \mathrm{mM}$ sodium phosphate, $\mathrm{pH} 8.5$ and $0.01 \%$ SDS, and printed onto slides in a final spotting concentration of $30 \mathrm{nM}$. The epoxy slides were spotted at 
Table 1 Nucleotide sequences of PCR primers and probes

\begin{tabular}{|c|c|c|c|}
\hline Oligonucleotide & Sequence $\left(5^{\prime}-3^{\prime}\right)$ & Target bacteria & Source \\
\hline \multicolumn{4}{|c|}{ DNA microarray amplification } \\
\hline $16 S 27 f$ & GAGAGTTTGATCCTGGCTCAG & Almost all eubacteria & Modified oligo fD1[38] \\
\hline $16 S 1495 r$ & CTACGGCTACCTTGTTACGA & Almost all eubacteria & Modified oligo fD1[38] \\
\hline \multicolumn{4}{|c|}{ qPCR amplification } \\
\hline CbqPCR F & GGGAAACTCGGGCTAATACC & Coxiella spp. & This study \\
\hline CbqPCR R & CACGAGGTCCGAAGATCC & Coxiella spp. & This study \\
\hline CbqPCR P & FAM-CCCGCTITGCTCCAAAGAGATTATG-TAMRA & Coxiella spp. & This study \\
\hline RcqPCR F & GCTTAACCTCGGAATTGCTT & Rickettsia spp. & This study \\
\hline RcqPCR R & CGTCAGTTGTAGCCCAGATG & Rickettsia spp. & This study \\
\hline RcqPCR P & HEX-CCTTCGCCACCGGTGTTCCT-TAMRA & Rickettsia spp. & This study \\
\hline FrqPCR F & ATTAAAGGTGGCCTTTGTGC & Francisella spp. & This study \\
\hline FrqPCR F2 & ATTAAAGGTGGCTTTCGGGC & Francisella spp. & This study \\
\hline FrqPCR R & ACCAACTAGCTAATCCAACGC & Francisella spp. & This study \\
\hline FrqPCR P & Cy5-AGGCTCATCCATCTGCGGCA-BHQ2 & Francisella spp. & This study \\
\hline \multicolumn{4}{|l|}{ Capture probes } \\
\hline A3 & CGGCTATCTGGTCCGGTACTGAC & Anaplasma spp. & [28] \\
\hline Av & GCTGAATGTGGGGATTIITATCTCTGT & Anaplasma spp. & [28] \\
\hline $\mathrm{Be}$ & AAGGGTGGAATCTGTTGATATCAGG & Borrelia spp. & [28] \\
\hline $\mathrm{Bg} 1$ & CTGGTGTAAGGGTGGAATCTGTTGA & Borrelia spp. & [28] \\
\hline Bg2 & TCAGAAAGAATACCGGAGGCGAAGG & Borrelia spp. & This study \\
\hline Bsp1 & GGAATAAGCTITGTAGGAAATGGCAAAGTGATGACG & Borrelia spp. & This study \\
\hline Bv & ACTTGGTGTTAACTAAAAGTTAGTACCGA & Borrelia spp. & [28] \\
\hline Bv2 & TATCAGGAAGAATACCGGAGGCGAA & Borrelia spp. & This study \\
\hline $\mathrm{C} 1$ & AATATCCTTGGGCGTTGACGTTACC & Coxiella spp. & [28] \\
\hline Cv & ACTAGCTGTTGGGAAGTTCACTTCTTAGT & Coxiella spp. & [28] \\
\hline F1v & ACTAGCTGTTGGAGTCGGTGTAAAGG & Francisella spp. & [28] \\
\hline F2 & TAGAGGAATGGGGAATTTCTGGTGT & Francisella spp. & [28] \\
\hline $\mathrm{F} 2 \mathrm{v}$ & ACTAGCTGTTGGATTCGGTGTAAAGG & Francisella spp. & [28] \\
\hline $\mathrm{Fa}$ & AATAGCCTTGGGGGAGGACGTTAC & Francisella spp. & [28] \\
\hline NM & CTATTAAACTAGAGATCGAGAGAGGATAGTGG & C. Neoehrlichia mikurensis & This study \\
\hline R1 & TAGAGTRTAGTAGGGGATGATGGAA & Rickettsia spp. & [28] \\
\hline Rv & GCTAGATATCGGAAGATTCTCTITCGG & Rickettsia spp. & [28] \\
\hline $\operatorname{Re}$ & GTGGTCGCGGATCGCAGAGA & Rickettsia spp. & [28] \\
\hline
\end{tabular}

room temperature in 55-70\% relative humidity and stored overnight at room temperature. All capture probes were spotted onto slides in triplicate. These prefabricated slides were blocked in a prehybridization solution ( $5 \times$ SSC, $0,1 \%$ SDS and $0.1 \mathrm{mg} / \mathrm{ml} \mathrm{BSA}$ ) at $42^{\circ} \mathrm{C}$ for 1 hour, washed 3 times in $0.1 \times$ SSC for 5 minutes and once more in purified water for 30 seconds. After washing, the slides were dried by centrifugation at $1600 \times \mathrm{g}$ for 2 minutes. The Cy5labelled target PCR products from the nested PCRs were diluted in a hybridization solution consisting of $5 \times \mathrm{SSC}$, $10 \%$ formamide, $0.1 \%$ SDS and $0.1 \mathrm{mg} / \mathrm{ml}$ of sonicated salmon sperm DNA, denaturated for 5 minutes in boiling water, shortly spun down, and cooled to room temperature. The target PCR products were pipetted onto microarray slides and covered with cover slips. The hybridization was performed at $42^{\circ} \mathrm{C}$ for $12-16$ hours. After hybridization, the microarray slides were immersed in $2 \times$ SSC and 0.1\% SDS at $42^{\circ} \mathrm{C}$ to gently release the cover slips from the slides and washed again for 5 minutes in $2 \times$ SSC and 0.1\% SDS at $42^{\circ} \mathrm{C}$. The final washing consisted of two washes in $1 \times$ SSC for 2 minutes at room temperature and two washes in $0.1 \times$ SSC for 1 minute at room temperature. The slides were dried by centrigufation at $1600 \times \mathrm{g}$ for 2 minutes and scanned at $635 \mathrm{~nm}$ on a MARs Micro Array Scanner 
(DITABIS - Digital Biomedical Imaging Systems AG, Germany) with SpotScout Pro at $50 \mu \mathrm{m}$ resolution. The fluorescence intensity for a given spot is represented by the mean feature pixel intensity at $635 \mathrm{~nm}$ minus the median background intensity at this wavelength (F635 Mean B635). Since all slides were spotted in triplets, the reported measurements are the mean values of three measurements. An "M probe" consisting of mixed PCR fragments from the first PCRs was used as a positive control (details were previously published in Blaškovič and Barák [28]. M probe fragments were spotted onto the microarray plates in three places as capture probes. This was done in triplicate. In addition to their use as a positive control, the M probes also aided in grid location during the scanning and made it possible to performing the final negative sample evaluation. The lower border of a saturated spot was defined as $25 \%$ of the saturated spot area. All fluorescence intensity values were normalized with respect to the $M$ probe and are reported as percentages of the $M$ probe intensity (defined to be $100 \%)$.

\section{Determination of the limit of detection (LOD)}

The concentration of genomic DNA isolated from the targeted tick-borne bacteria was quantified using a GeneQuant spectrophotometer (LABFISH, Germany) and the number of copies per $\mu \mathrm{l}$ was calculated using an on-line DNA copy number calculator [41]. The DNA was diluted to a starting concentration of $10^{5}$ copies $/ \mu \mathrm{l}$ for Coxiella spp. and Rickettsia spp. and $10^{4}$ copies/ $\mu \mathrm{l}$ for Francisella spp. This starting solution was then serially diluted 10-fold to prepare a series of solutions from $10^{5}$ or $10^{4}$ copies of genomic DNA (gDNA) per $\mu$ l down to $1 \mathrm{copy} / \mu \mathrm{l}$ (that is, there were six dilutions: $10^{5}, 10^{4}$, $10^{3}, 10^{2}, 10^{1}$, and $10^{0}$ ). To determine the microarray LOD, $1 \mu$ of these diluted DNAs were used as templates for the amplifications of the rrs gene and the products of these first PCRs were Cy5-labeled using nested PCRs as described above. The labeled amplicons were then hybridized with the prefabricated microarray and scanned and evaluated.

A very similar approach was used to determine the detection limit of qPCR. The same DNA dilutions were used as the templates and genus specific oligonucleotides and probes were used to amplify the rrs genes.

The highest target DNA dilution which still returned a positive result was determined the detection limit of the DNA microarray or qPCR. Three independent experiments were run for each dilution series. Each qPCR experiment consisted of one of the target gDNA dilutions and a mix of non-target gDNAs as negative control. To determine the detectable copy number, an absolute quantification method was employed. The mean quantification cycle $(\mathrm{Cq})$ was converted to a log starting quantity using a linear equation derived from the standard curves.

\section{Results}

Development of a DNA microarray for the detection of tick-borne pathogens

A DNA microarray is an efficient and simple tool for detecting a wide spectrum of tick-borne pathogens in a single step. A first generation DNA microarray for detecting tick-borne bacteria was developed previously by Blaškovič and Barák [28]. In that study, the amplification of target DNA by symmetric/asymmetric PCR appeared to be quite complicated. The authors were not able to obtain a single stranded amplicon using asymmetric PCR when DNA from B. burgdorferi, C. burnetii and $R$. africae was used as a template. They therefore recommended using symmetric PCR for the amplification of all targets involved in the study. The limit of detection (LOD) was also not determined for this assay.

The first steps for upgrading this DNA microarray were to improve the amplification of the $16 \mathrm{~S}$ rDNA ( $r r s$ ) gene to enable detection of all bacteria present in the analyzed samples and to increase the efficiency of Cy5-dUTP incorporation into the PCR products. A nested PCR was designed whose first cycle was used to amplify the target gene in high yield. In the second cycle, Cy5-dUTP was incorporated into the PCR amplicon. Crucial for the success of this PCR was the selection of a Taq-polymerase, which was able to both efficiently incorporate modified nucleotides into PCR fragments and to amplify the gene in high yield. Several types of Taq-polymerases, including DyNAzyme EXT DNA Polymerase, Taq DNA Polymerase, (Thermo Fisher Scientific, USA), Taq DNA Polymerase with Standard Taq (Mg-free) Buffer (New England Biolabs, USA), and many cycling conditions were tested (not shown). The best Taq-polymerase appeared to be Taq Polymerase/ high yield from Jena Bioscience (Germany). The final annealing temperature was $52^{\circ} \mathrm{C}$. In both nested PCR cycles, the same, so-called "catch-all" primers $16 \mathrm{~S} 27 \mathrm{f}$ and $16 \mathrm{~S} 1495 \mathrm{r}$ were used. These primers are slightly modified versions of the previously published eubacterial primers fD1 and rP2 [38]. 16S27f is the same as fD1 but with an additional $\mathrm{G}$ at the $5^{\prime}$ end. Modification of rP2 included CT addition to the $5^{\prime}$ end of 16 S1495r and truncation of three nucleotides from the $3^{\prime}$ end (Table 1). The Cy5labeled PCR products were precipitated in the presence of ammonium sulphate and ethanol [42] and the pellets were resuspended in the required volume of hybridization solution (see Methods).

\section{Coupling of target Cy5-labeled amplicons with capture probes}

The capture probes Bv, Be, Bg1, C1, Cv, Av, A3, F1v, F2v, Fa, F2, R1, Rv and Re were previously designed to bind Cy5-labeled PCR-generated fragments encoding the $16 \mathrm{~S}$ rDNA genes of Borrelia spp., Coxiella spp., Anaplasma spp., Francisella spp. and Rickettsia spp., respectively [28]. 
Even though the hybridization conditions and posthybridization washes had been changed in the present study, they still reacted specifically. To increase the ability of the assay to detect the targeted bacteria, new capture probes for Borrelia spp. (Bg2, Bsp, Bv2) and Candidatus N. mikurensis (NM) were designed (see Table 1). All capture probes were printed onto epoxy slides in triplets in final concentrations of $30 \mu \mathrm{M}$. A Cy5-labeled PCR product encoding the 16S rDNA (rrs) of Borrelia spp., Coxiella spp., Anaplasma spp., Rickettsia spp. and Francisella spp. was generated by amplifying purified DNA from bacterial stocks. These Cy5-amplicons were then hybridized with the capture probes. Cy5-amplicons encoding the $16 \mathrm{~S}$ rDNA of Candidatus N. mikurenses were generated using DNA isolated from ticks. The positivity of the tick for Candidatus N. mikurenses was analyzed in a previous study by qPCR [43].

The ability of the individual capture probes to bind the same target DNA differs depending on the status of the Cy5-amplicons or the quality of the spotted probes or epoxy slides. Our results clearly show that the coupling of capture probes with Cy5-PCR fragments generated from DNA isolated from ticks was not as efficient as that with Cy5-PCR amplicons generated from purified DNA. Thus, the measured fluorescence intensity of the $\mathrm{M}$ probe (positive control) and positive capture probes had to be normalized after scanning. The fluorescence intensity is expressed as the mean feature pixel intensity of the positive spot at $635 \mathrm{~nm}$ minus the median background at $635 \mathrm{~nm}$ (F635 Mean - B635).

The fluorescence intensity of the $M$ probe and the positive capture probes for Coxiella spp., Borrelia spp., Francisella spp., Rickettsia spp. and Anaplasma spp., gave much stronger positive signals than those obtained after the hybridization of a Cy5-labeled amplicon with DNA isolated from a tick coinfected with Borrelia spp. and Candidatus N. mikurensis (Figure 1A). In order to compare these different fluorescence values, the fluorescence intensity of each positive signal was expressed as a percentage of the fluorescence of the $M$ probe. The DNA microarray for Candidatus N. mikurensis revealed a possible co-infection with Borrelia spp. but the percentage of fluorescence intensities was quite low, only $12 \%$ and $9 \%$ respectively of the fluorescence intensity of the $M$ probe. Such a low signal was considered only ambiguously positive and required further analysis.

To determine if a sample with such a low fluorescence tests positive or negative, it was necessary to determine the limit of detection (LOD) of the DNA microarray. To do this, a series of 10 -fold dilutions, ranging from $10^{5}$ genome copies per $\mu \mathrm{l}$ down to $1 \mathrm{copy} / \mu \mathrm{l}$, was prepared from DNA of the targeted tick-borne bacteria. These dilutions were then used as templates for nested PCRs and DNA microarrays. The fluorescence intensities of the capture probes were compared to that of the $M$ probe (Figure 2). The fluorescence intensity of the $\mathrm{Cv}$ capture probe specific for Coxiella spp. was $120 \%$ when $10^{5}$ copies were used as template DNA, $12 \%$ when $10^{4}$ copies and $10 \%$ when $10^{3}$ copies were used. $10^{2}$ copies of template DNA apparently did not bind the capture probes and no fluorescence intensity could be measured; the 10 copies and 1 copy dilutions were also negative. So, the maximal dilution of template DNA, which is detectable by the DNA microarray is $10^{3}$ copies/ $\mu \mathrm{l}$, which gives a fluorescence intensity $10 \%$ of that of the $M$ probe. Therefore, a sample should be evaluated as positive when the mean fluorescence intensity is at least $10 \%$ of the mean fluorescence intensity of the M Probe. Thus, samples with values close to this cut off limit will require other analyses, such as some previously published $\mathrm{qPCR}$ protocols $[20,43]$, to verify their results. An analysis using the protocols of Courtney et al. [20] and Jahfari et al. [43] confirmed that the signal at the $12 \%$ level for the Candidatus N. mikurensis specific probe, as well as the signal at $9 \%$ for the B. burgdorferi s.l. probe both represent positive samples (data not shown).

The specificity of the DNA microarray was tested using mixed genomic DNAs from many bacterial species, including DNA from tick-borne pathogens, but excluding the target DNA for which the chip was designed. No unspecific cross-reactivity between the capture probes and genomic DNAs was detected (data not shown).

\section{Development of qPCR based on the variability of rrs specific for detection of Francisella spp., Rickettsia spp. and Coxiella spp.}

This newly developed DNA microarray represents our first line approach for the detection of tick-borne bacteria. To validate the results obtained with the DNA microarray, we used quantitative PCR. It was also necessary to verify the positive detection limits for Candidatus N. mikurensis (F635 Mean - B635 of 12\%) and B. burgdorferi s.l. spp. (F635 Mean - B635 of 9\%) with this method. Duplex qPCR for the simultaneous detection of $A$. phagocytophilum and Borrelia burgdorferi s.l. was developed by Courtney et al. [20]. They employed the $m s p 2$ gene and the 23S rDNA gene, respectively, for the detection of these two pathogenic species. A real-time PCR assay for the detection of Candidatus N. mikurensis was developed by Jahfari et al. [43]. These two protocols were used to confirm the Candidatus N. mikurensis results from the DNA microarray. In addition, two real-time PCRs based on two putative target genes for hypothetical proteins FTT0376 and FTT0523 were developed to distinguish the pathogenic subspecies Francisella tularensis (subsp. tularensis, holarctica and mediaasiatica) from nonpathogenic $F$. philomiragia or F. novicida [44]. Because FTT0376 and 


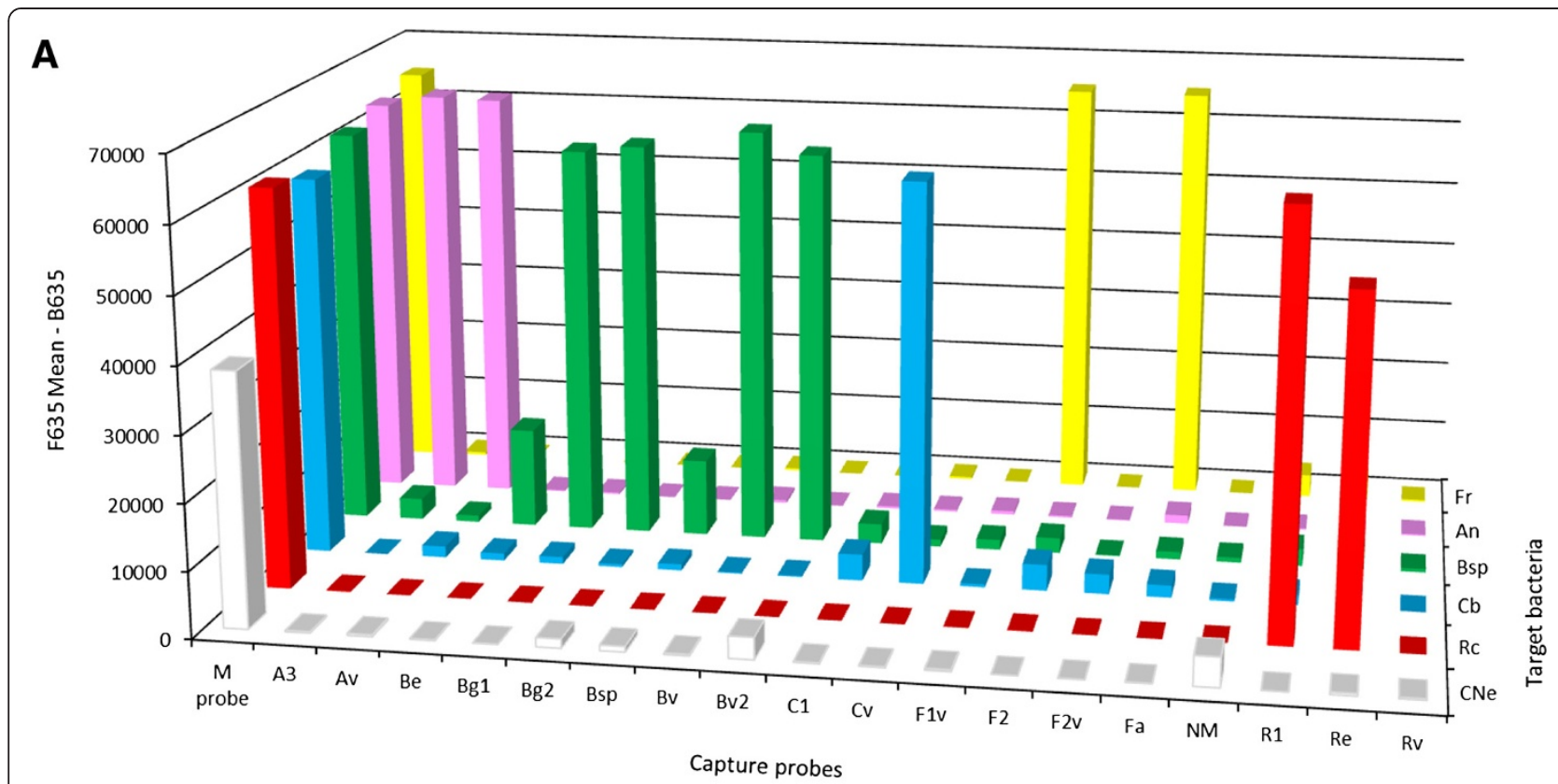

B

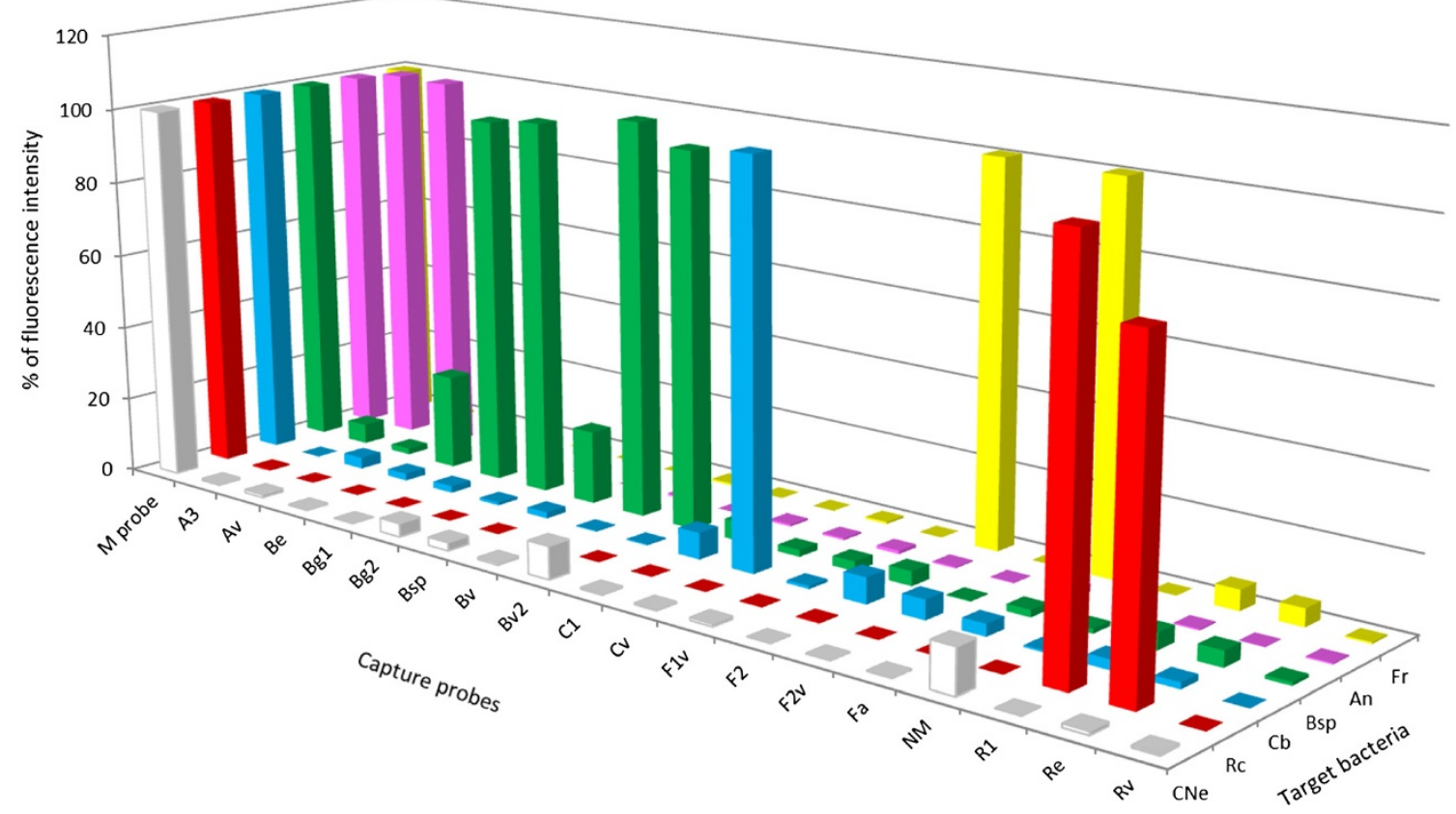

Figure 1 Specificity of capture probes and target bacteria detected by the DNA microarray. (A) Fluorescence intensity at $635 \mathrm{~nm}$ (F634Mean-B635) of specific capture probes coupled to target Cy5-labeled amplicons. (B) Fluorescence intensity expressed as a percentage of the fluorescence intensity of the capture probe in relative to $100 \%$ of the fluorescence intensity of the M probe (positive control). All capture probes are listed in Table 1. The targeted bacteria were (CNe) Candidatus Neoehrlichia mikurensis, (Rc) Rickettsia spp., (Cb) Coxiella spp., (Bsp) Borrelia spp., (An) Anaplasma spp., (Fr) Francisella spp.

FTT0523 real-time PCRs detect only the pathogenic but not the nonpathogenic Francisella subspecies, this approach is not suitable as a confirmatory method for our DNA microarray analysis, since all Francisella species is our primary target. For this reason, we developed a qPCR employing the $16 \mathrm{~S}$ rDNA (rrs) gene in order to detect all
Francisella species, and two other qPCRs, to detect the Rickettsia spp. and Coxiella spp. The primers and oligonucleotide dual-labeled probes were designed using GenScript Real-time PCR (TaqMan) Primer Design online software [45] based on the alignment of the rrs genes of all tick-borne bacteria of interest. These probes and 


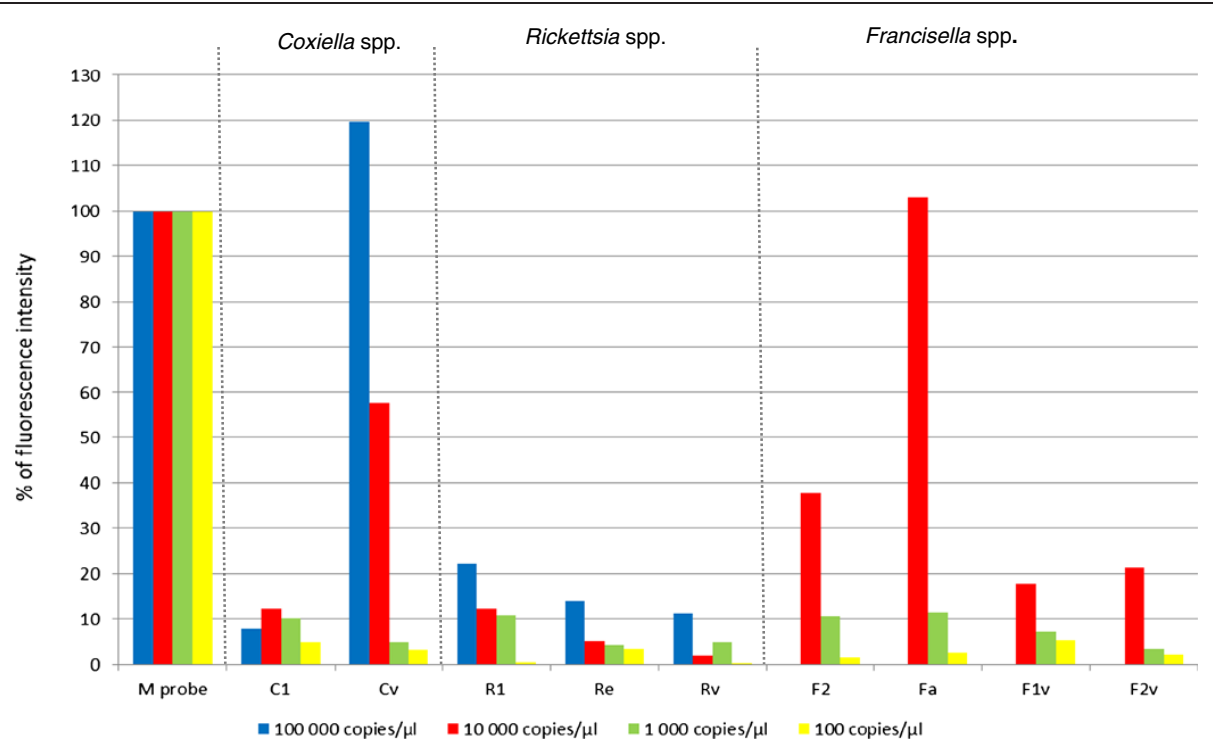

Figure 2 The DNA microarray limit of detection (LOD). LOD for Rickettsia spp., Coxiella spp., and Francisella spp. was determined as the highest dilution of genomic DNA that still tested as positive. $10^{3}$ genome copies exhibited $10 \%$ of the fluorescence intensity of the $\mathrm{M}$ probe, while $10^{2}$ genome copies produced no detectible signal; the LOD was therefore determined to be $10^{3}$ copies and $10 \%$ of the positive control. All capture probes are listed in Table 1. The fluorescence intensity of the capture probes is expressed as a percentage of the fluorescence intensity of the $\mathrm{M}$ probe.

primers are specific for the hypervariable region of the rrs gene, which are different for every genus (Table 1). Their specificities were tested against mixed genomic DNA from all possible tick-borne bacteria and other bacterial genomic DNA present in our laboratory stocks.

Because of the slight variation in the hypervariable region of the Francisella spp. rrs sequences, two forward primers were designed. Forward primer FrqPCRF preferentially binds $F$. piscicida and $F$. philomiragia, while forward primer FrqPCRF2 is specific for F. tularensis subsp. holarctica, mediaasiatica, tularensis and novicida. All qPCRs were specific when tested against mixed genomic DNA from other bacteria.

\section{Determination of qPCR detection limit}

Limits of detection for all three qPCRs were determined based on the maximum dilution of genomic DNA from the target bacteria which still tested positive. To develop a qPCR specific for Coxiella spp. and Rickettsia spp., their genomic DNAs were diluted in a series of 10 -fold dilutions, from $10^{5}$ copies/ $\mu$ l to 1 copy/ $\mu$ l. Due to the low concentration of genomic DNA in Francisella spp., the starting copy number of the series was only $10^{4}$ copies/ $\mu$ l. The absolute quantifications of the detectable genome copy number from Francisella spp., Coxiella spp. and Rickettsia spp. is shown in Figure 3. The standard curve amplification efficiencies (E), regression coefficients $\left(R^{2}\right)$, slopes (s) and $y$-intercept (y-int) are listed in Table 2. The amplification efficiencies of all qPCRs were 95\%, 102\% and $96 \%$ for Rickettsia spp., Coxiella spp. and Francisella spp., respectively. The sensitivity of qPCR for Rickettsia spp. was determined to be $10^{2}$ genome copies; for Coxiella spp., 10 genome copies and for Francisella spp., only 1 genome copy. Considering the mean sizes of the genomes (2.2 Mb for Coxiella spp., $2 \mathrm{Mb}$ for Francisella spp. and 1.2 $\mathrm{Mb}$ for for Rickettsia spp.), the copy numbers determined for the LOD correspond to approximately $22 \mathrm{fg}$ of gDNA for Coxiella spp., 2.1 fg gDNA for Francisella spp. and $140 \mathrm{fg}$ gDNA for Rickettsia spp.

\section{Discussion}

Broad epidemiological studies of veterinary or human importance and clinical diagnostic laboratories require the application of high-throughput, large scale assays allowing the simultaneous detection of all possible microorganisms present in a given sample. Such methods can involve broad range PCRs, multiplex quantitative PCR, molecular beacons or DNA microarrays. Usually these methods employ universal genes, such as the $16 \mathrm{~S}$ rDNA rrs gene, the $23 \mathrm{~S}$ rDNA gene, or, occasionally, genes specific for each bacterial genus or species identified in previous studies. In the last decade, DNA microarrays have become one of the most powerful approaches for the simultaneous detection of several bacterial species. They have many possible applications, including identifying bioterror agents [46] and detecting causative pathogens in clinical samples or epidemiological studies $[31,47,48]$. In clinical diagnostics, it is essential to know all possible co-infections of the patient in order to consider all potential complications, and thus 


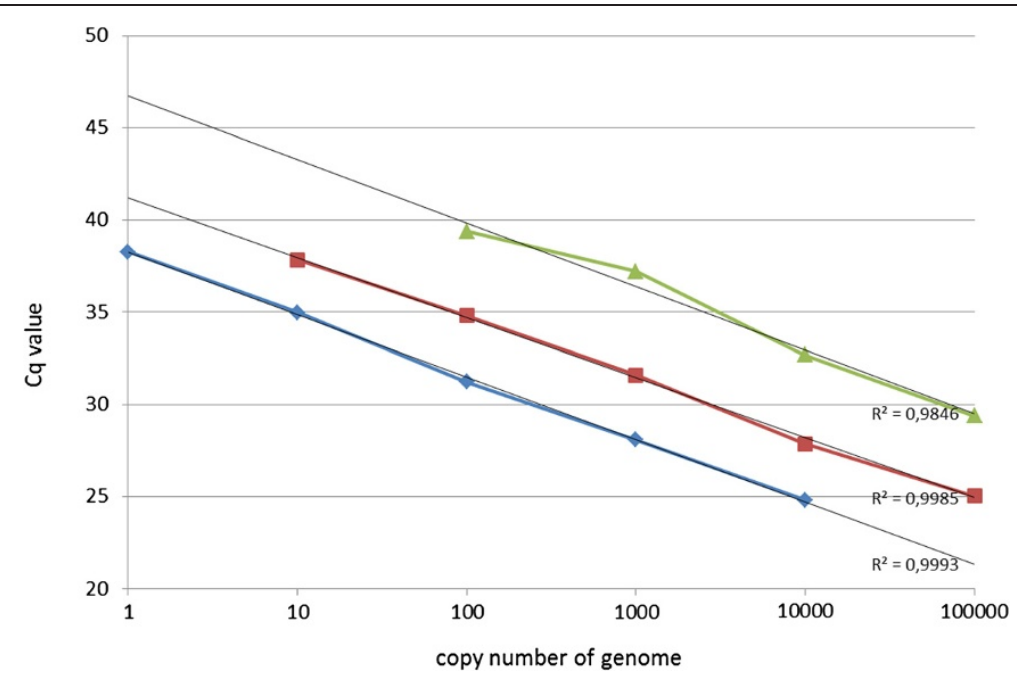

Figure 3 Absolute quantification of the detectable genome copy numbers from tick-borne bacteria. Quantitative PCRs were developed for Francisella spp. (blue curve), Coxiella spp. (red curve) and Rickettsia spp. (green curve). The trendlines and $\mathrm{R}^{2}$ values were generated using Microsoft Excel based on the average of the cycle of quantification values $(\mathrm{Cq})$ and the genome copy numbers.

prescribe an effective treatment. Along with other methods, DNA microarrays allow the detection of all agents of a multiple infection in one step.

The major focus of this study was to develop an easy to use, second generation low-density DNA microarray for the simultaneous detection of the many kinds of bacteria present in tick samples. This technique has potential applications in clinical and veterinary laboratories and is also suitable for broad epidemiological studies. The DNA microarray consists of genus-specific capture probes for Borrelia spp., Coxiella spp., Anaplasma spp., Francisella spp. and Rickettsia spp. that were designed for the first generation DNA microarray [28] along with new capture probes Bsp, Bg2 and Bv2 which were designed to increase the possibility of detecting all Borrelia species. In addition, a specific NM probe was designed to detect the newly emerged tick-borne bacterium Candidatus N. mikurensis. The modified solution compositions, hybridization conditions and post-hybridization washes did not affect specificity either of the original or the new capture probes. Capture probe specificity was analyzed by hybridization with Cy5-dUTP labeled PCR fragments generated by PCR on a template containing mixed genomic DNA from other, non-target bacteria.

The sensitivity of the first generation DNA microarray was not tested [28], and thus it was necessary to test the

Table 2 The parameters of the standard curves of qPCRs

\begin{tabular}{lllll}
\hline Template gDNA & $\mathbf{s}$ & $\mathbf{R}^{\mathbf{2}}$ & $\mathbf{E}$ & Y-int \\
\hline Rickettsia spp. & $-3,452$ & 0,984 & $94,8 \%$ & 46,75 \\
Coxiella spp. & $-3,266$ & 0,999 & $102,4 \%$ & 41,2 \\
Francisella spp. & $-3,435$ & 0,999 & $95,5 \%$ & 38,294 \\
\hline
\end{tabular}

sensitivity of the second generation DNA microarray by determining the limit of detection (LOD). The LOD of our second generation DNA microarray was determined to be the highest dilution of the target genomic DNA that still tested as positive. The LOD was determined to be $10^{3}$ target genome copies based on hybridization with specific capture probes at different dilutions. Given the mean genome sizes of the targeted bacteria, the limit of detection is about $\sim 1-2$ pg of genomic DNA. This sensitivity is comparable to that of the low-density DNA microarrays developed to detect tick-borne bacteria such as Borrelia spp. [31] or other array techniques developed to detect potential biological weapons, with detection limits $\sim 10^{2}-10^{4}$ target genome copies $[29,30]$.

Differences were observed in the fluorescence signal intensities produced by the DNA microarray, depending on whether the target DNA was directly purified from bacteria, or was isolated from an infected tick. These differences are likely due to the presence of junk DNA from the tick and a low concentration of the target bacterial DNA. The crucial steps of PCR amplification and Cy5-labeling on such targets are also more complicated. Both of these factors can lead to a low level of fluorescence intensity following hybridization, making interpretation of a positive signal difficult. This situation was observed when genomic DNA isolated from a tick coinfected with Candidatus N. mikurensis and Borrelia spp. was used as a template for DNA microarray analysis. The mean fluorescence of the capture probes was at the detection limit. It was therefore necessary to develop qPCRs using dual labeled TaqMan probes (Table 1). Since duplex qPCR protocols have been developed to detect $A$. phagoctytophilum and B. burgdorferi 
s.l. [20], and real-time PCR protocols exist for Candidatus $\mathrm{N}$. mikurensis [43], the presence or absence of these pathogens could be verified. Quantitative PCR protocols were developed to detect Rickettsia spp., Coxiella spp. and Francisella spp. Oligonucleotide probes were designed according to the hypervariable regions of the rrs gene, which are specific for each bacterial genus; both the specificity and sensitivity of the procedure were evaluated. As for the DNA microarray, the qPCR specificity was determined by amplifying the target gene on a template containing mixed genomic, non-target DNAs other than the genomic DNA of the target bacteria. No cross-reactivity with any of these gDNAs was observed. To test the sensitivity of each qPCR, a series of 10 -fold dilutions of the target genomic DNAs from Rickettsia spp., Coxiella spp. and Francisella spp. were employed in the amplification, with the final efficiencies of $95 \%, 102 \%$ and $96 \%$, respectively. The highest dilution that was evaluated as positive was $10^{2}$ genome copies from Rickettsia spp., 10 genome copies from Coxiella spp. and only 1 genome copy from Francisella spp.; these corresponded to approximately $140 \mathrm{fg}$ of Rickettsia spp. genomic DNA, $22 \mathrm{fg}$ of Coxiella spp. genomic DNA and 2.1 fg of Francisella spp. genomic DNA. The limits of detection for all three qPCRs assays were at the breakpoint of qPCR detection and were very similar to those of multiplex qPCR for $C$. burnetii targeted to the com1, icd and IS1111 genes [49], real-time PCR for F. piscicida targeted to the rrs gene [39], and qPCR developed to detect a Rickettsia-like microorganism, which is responsible for strawberry disease in fish [40]. The qPCRs for the detection of all three pathogens appeared to be more sensitive than the DNA microarray. The qPCR for the detection of Francisella spp. was more sensitive than that of either Coxiella spp. or Rickettsia spp. This may be due to the existence of three copies of the rrs gene in the Francisella genomes present in the Ribosomal RNA Operon Copy Number Database [50] compared to only one copy of the rrs gene in Rickettsia prowazekii [51] and C. burnetii [52].

It should be noted that many ticks harbor non-pathogenic bacteria, including Coxiella-like [53-56], Rickettsia-like [57-59] and Francisella-like [60,61] endosymbionts, which are in a mutualistic relationship with the tick. These primary endosymbionts can provide nutrition to the host [62]. They likely evolved over a long time and they are characterized with a reduced genome [63]. However, they still retain ribosomal RNA genes which have a relatively high level of similarity to those found in pathogenic organisms. For example, the rrs gene of the Amblyomaassociated, Coxiella-like endosymbiont has $93 \%$ indentity to the C. burnetii rrs [64]. The role of the secondary endosymbionts is unknown, but they can serve as protection against other pathogens [65]. The DNA microarray developed here, together with the qPCRs, is targeted to the hypervariable regions of $r r s$ genes. A positive signal generated using this approach therefore does not necessarily indicate that the host vector contains a pathogenic bacteria. A sequence analysis of the final result is needed to distinguish between endosymbiont and pathogen in these samples.

\section{Conclusion}

We have developed a sophisticated detection system for the simultaneous detection of bacteria present in reservoir hosts, tick-vectors, and clinical specimens, based on a second generation DNA microarray employing the genus-specific, hypervariable regions of the rrs gene. These hypervariable sequences were used to design capture probes for the DNA microarray as well as primers and TaqMan probes for qPCRs. The qPCRs can be used to verify the positive results from the DNA microarray. Both methods display a high level of specificity and sensitivity. The limit of detection for the DNA microarray was $10^{3}$ genome copies. Quantitative PCRs were developed for Rickettsia spp, Coxiella spp. and Francisella spp. and the limits of detection were determined. Finally, previously developed and published $\mathrm{qPCR}$ procedures are available for the verification of presence of the other bacteria involved in this study.

\section{Competing interests}

The authors declare that they have no competing interests.

\section{Authors' contributions}

The study was designed by JM and IB. The DNA samples were provided by MD. JM and MD performed laboratory experiments. JM and IB conducted genetic analysis and evaluated microarray and qPCR data. The final manuscript was written by JM, IB and MD. All authors read and approved the final version of the manuscript.

\section{Acknowledgements}

We thank Jacob Bauer for helpful comments. This publication is the result of the project implementation: Development of diagnostic procedures for detection of tick-borne pathogens and procedures for the preparation of vaccines against ticks (ITMS code: 26240220044) supported by the Research \& Development Operational Programme funded by the ERDF and by the Slovak Research and Development Agency under contract No. APW - 0267-10.

\section{Author details}

${ }^{1}$ Institute of Molecular Biology, Slovak Academy of Sciences, Dúbravska cesta 21, 845 51, Bratislava, Slovak Republic. ${ }^{2}$ Institute of Zoology, Slovak Academy of Sciences, Dúbravska cesta 9, 845 06, Bratislava, Slovak Republic. ${ }^{3}$ Institute of Parasitology, Slovak Academy of Sciences, Hlinkova 3, 040 01, Košice, Slovak Republic.

Received: 1 August 2013 Accepted: 12 September 2013 Published: 18 September 2013

\section{References}

1. Franke J, Hildebrandt A, Dorn W: Exploring gaps in our knowledge on Lyme borreliosis spirochaetes-updates on complex heterogeneity, ecology, and pathogenicity. Ticks Tick Borne Dis 2013, 4:11-25.

2. Van Dam AP, Kuiper H, Vos K, Widjojokusumo A, de Jongh BM, Spanjaard L, Ramselaar AC, Kramer MD: Different genospecies of Borrelia burgdorferi are associated with distinct clinical manifestations of Lyme borreliosis. Clin Infect Dis 1993, 17:708-717. 
3. Gern L: Borrelia burgdorferi sensu lato, the agent of lyme borreliosis: life in the wilds. Parasite 2008, 15:244-247. Review.

4. Margos G, Vollmer SA, Ogden NH, Fish D: Population genetics, taxonomy, phylogeny and evolution of Borrelia burgdorferi sensu lato. Infect Genet Evol 2011, 11:1545-1563.

5. Bunikis J, Tsao J, Garpmo U, Berglund J, Fish D, Barbour AG: Typing of Borrelia relapsing fever group strains. Emerg Infect Dis 2004, 10:1661-1664.

6. Dumler JS, Barbet AF, Bekker CPJ, Dasch GA, Palmer GH, Ray SC, Rikihisa Y, Rurangirwa FR: Reorganization of Genera in the families Rickettsiaceae and Anaplasmataceae in the order Rickettsiales; unification of some species of Ehrlichia with Anaplasma, Cowdria with Ehrlichia, and Ehrlichia with Neorickettsia; description of six new species combinations; and designation of Ehrlichia equi and "HGE agent" as subjective synonyms of Ehrlichia phagocytophilum. Int J Syst Evol Microbiol 2001, 51:2145-2165.

7. Woldehiwet Z: The natural history of Anaplasma phagocytophilum. Vet Parasitol 2010, 167:108-122.

8. Kawahara M, Rikihisa Y, Isogai E, Takahashi M, Misumi H, Suto C, Shibata S, Zhang C, Tsuji M: Ultrastructure and phylogenetic analysis of 'Candidatus Neoehrlichia mikurensis' in the family Anaplasmataceae, isolated from wild rats and found in Ixodes ovatus ticks. Int J Syst Evol Microbiol 2004, 54:1837-1843.

9. Welinder-Olsson C, Kjellin E, Vaht K, Jacobsson S, Wennerås C: First case of human "Candidatus Neoehrlichia mikurensis" infection in a febrile patient with chronic lymphocytic leukemia. J Clin Microbiol 2010, 48:1956-1959.

10. Fehr JS, Bloemberg GV, Ritter C, Hombach M, Lüscher TF, Weber R, Keller PM: Septicemia caused by tick-borne bacterial pathogen Candidatus Neoehrlichia mikurensis. Emerg Infect Dis 2010, 16:1127-1129.

11. Pekova S, Vydra J, Kabickova H, Frankova S, Haugvicova R, Mazal O, Cmejla R, Hardekopf DW, Jancuskova T, Kozak T: Candidatus Neoehrlichia mikurensis infection identified in 2 hematooncologic patients: benefit of molecular techniques for rare pathogen detection. Diagn Microbiol Infect Dis 2011, 69:266-270.

12. Von Loewenich FD, Geissdörfer W, Disqué C, Matten J, Schett G, Sakka SG, Bogdan C: Detection of "Candidatus Neoehrlichia mikurensis" in two patients with severe febrile illnesses: evidence for a European sequence variant. J Clin Microbiol 2010, 48:2630-2635.

13. Sjöstedt A: Tularemia: history, epidemiology, pathogen physiology, and clinical manifestations. Ann N Y Acad Sci 2007, 1105:1-29.

14. Rath N, Rath A: Rickettsial Infections: Indian perspective. Indian Pediatr 2010, 47:157-164.

15. Beati L, Péter O, Burgdorfer W, Aeschlimann A, Raoult D: Confirmation that Rickettsia helvetica sp. nov. is a distinct species of the spotted fever group of rickettsiae. Int J Syst Bacteriol 1993, 43:521-526.

16. Beati L, Meskini M, Thiers B, Raoult D: Rickettsia aeschlimannii sp. nov., a new spotted fever group rickettsia associated with Hyalomma marginatum ticks. Int J Syst Bacteriol 1997, 47:548-554.

17. Cowan G: Rickettsial diseases: the typhus group of fevers-a review. Postgrad Med J 2000, 76:269-272.

18. La Scola B, Raoult D: Laboratory diagnosis of rickettsioses: current approaches to diagnosis of old and new rickettsial diseases. J Clin Microbiol 1997, 35:2715-2727.

19. Li H, Jiang JF, Liu W, Zheng YC, Huo QB, Tang K, Zuo SY, Liu K, Jiang BG, Yang $\mathrm{H}$, Cao WC: Human Infection with Candidatus Neoehrlichia mikurensis, China. Emerg Infect Dis 2012, 18:1636-1639.

20. Courtney JW, Kostelnik LM, Zeidner NS, Massung RF: Multiplex real-time PCR for detection of Anaplasma phagocytophilum and Borrelia burgdorferi. J Clin Microbiol 2004, 42:3164-3168.

21. Rymaszewska A: PCR for detection of tick-borne Anaplasma phagocytophilum pathogens: a review. Vet Med 2011, 56:529-536.

22. Marmion BP, Storm PA, Ayres JG, Semendric L, Mathews L, Winslow W Turra M, Harris RJ: Long-term persistence of Coxiella burnetii after acute primary Q fever. QJM 2005, 98:7-20.

23. Subramanian G, Sekeyova Z, Raoult D, Mediannikov O: Multiple tick-associated bacteria in Ixodes ricinus from Slovakia. Ticks Tick Borne Dis 2012, 3:406-410.

24. Postic D, Assous M, Grimont PAD, Baranton G: Diversity of Borrelia burgdorferi sensu lato evidenced by restriction fragment length polymorphism of $r r f(5 S)-r r l(23 S)$ intergenic spacer amplicons. Int J Syst Bacteriol 1994, 44:743-752.

25. Derdakova M, Beati L, Pet'ko B, Stanko M, Fish D: Genetic variability within Borrelia burgdorferi sensu lato genospecies established by PCR-single -strand conformation polymorphism analysis of the $r$ ffA-rrlB intergenic spacer in Ixodes ricinus ticks from the Czech Republic. Appl Environ Microbiol 2003, 69:509-516.

26. Doolittle WF: Phylogenetic classification and the universal tree. Science 1999, 284:2124-2129.

27. Small J, Call DR, Brockman FJ, Straub TM, Chandler DP: Direct detection of $16 \mathrm{~S}$ rRNA in soil extracts by using oligonucleotide microarrays. App/ Environ Microbiol 2001, 67:4708-4716.

28. Blaskovic D, Barák I: Oligo-chip based detection of tick-borne bacteria. FEMS Microbiol Lett 2005, 243:473-478.

29. Wilson WJ, Erler AM, Nasarabadi SL, Skowronski EW, Imbro PM: A multiplexed PCR-coupled liquid bead array for the simultaneous detection of four biothreat agents. Mol Cell Probes 2005, 19:137-144.

30. Deshpande A, Gans J, Graves SW, Green L, Taylor L, Kim HB, Kunde YA Leonard PM, Li PE, Mark J, Song J, Vuyisich M, White PS: A rapid multiplex assay for nucleic acid-based diagnostics. J Microbiol Methods 2010, 80:155-163.

31. Houck JA, Hojgaard A, Piesman J, Kuchta RD: Low-density microarrays for the detection of Borrelia burgdorferi s.s. (the Lyme disease spirochete) in nymphal Ixodes scapularis. Ticks Tick Borne Dis 2011, 21:27-36.

32. Barbaro M, Bonfiglio A, Raffo L, Alessandrini A, Facci P, Barák I: Fully electronic DNA hybridization detection by a standard CMOS biochip. Sens Actuators B 2006, 118:41-46.

33. Barbaro M, Bonfiglio A, Raffo L, Alessandrini A, Facci P, Barák I: A CMOS, fully integrated sensor for electronic detection of DNA hybridization. IEEE Electron Device Letters 2006, 27:595-597.

34. Barlaan EA, Sugimori M, Furukawa S, Takeuchi K: Electronic microarray analysis of 16S rDNA amplicons for bacterial detection. J Biotechnol 2005, 115:11-21.

35. Cole JR, Chai B, Marsh TL, Farris RJ, Wang Q, Kulam SA, Chandra S, McGarrell DM, Schmidt TM, Garrity GM, Tiedje JM: The Ribosomal Database Project (RDP-II): previewing a new autoaligner that allows regular updates and the new prokaryotic taxonomy. Nucleic Acids Res 2003, 31:442-443.

36. Integrated DNA Technologie's OligoAnalyzer 3.1. http://eu.idtdna.com/ analyzer/applications/oligoanalyzer/default.aspx.

37. Basic Local Alignment Search Tool. http://blast.ncbi.n/m.nih.gov/Blast.cgi? PROGRAM=blastn\&BLAST PROGRAMS=megaBlast\&PAGE TYPE=BlastSearch \&SHOW_DEFAULTS=on\&LINK_LOC=blasthome.

38. Weisburg WG, Barns SM, Pelletier DA, Lane DJ: $16 \mathrm{~S}$ ribosomal DNA amplification for phylogenetic study. J Bacteriol 1991, 173:697-703.

39. Ottem KF, Nylund A, Isaksen TE, Karlsbakk E, Bergh Ø: Occurrence of Francisella piscicida in farmed and wild Atlantic cod, Gadus morhua L., in Norway. J Fish Dis 2008, 31:525-534.

40. Lloyd SJ, LaPatra SE, Snekvik KR, Cain KD, Call DR: Quantitative PCR demonstrates a positive correlation between a Rickettsia-like organism and severity of strawberry disease lesions in rainbow trout, Oncorhynchus mykiss (Walbaum). J Fish Dis 2011, 34:701-709.

41. DNA copy number calculation. http://www.thermoscientificbio.com/ webtools/copynumber/.

42. Sambrook J, Fritsch EF, Maniatis T: Molecular Cloning: A laboratory manual. 2nd edition. Cold Spring Harbor, NY: Cold Spring Harbor Laboratory Press; 1989.

43. Jahfari S, Fonville M, Hengeveld P, Reusken C, Scholte EJ, Takken W, Heyman P, Medlock J, Heylen D, Kleve J, Sprong H: Prevalence of Neoehrlichia mikurensis in ticks and rodents from North-west Europe. Parasit Vectors 2012, 5:74

44. Mitchell JL, Chatwell N, Christensen D, Diaper H, Minogue TD, Parsons TM, Walker B, Weller SA: Development of real-time PCR assays for the specific detection of Francisella tularensis ssp. tularensis, holarctica and mediaasiatica. Mol Cell Probes 2010, 24:72-76.

45. GenScript Real-time PCR (TaqMan) Primer Design. https://www.genscript.com/ ssl-bin/app/primer

46. Janse I, Bok JM, Hamidjaja RA, Hodemaekers HM, van Rotterdam BJ: Development and comparison of two assay formats for parallel detection of four biothreat pathogens by using suspension microarrays. PLoS One 2012, 7:e31958.

47. Garaizar J, Rementeria A, Porwollik S: DNA microarray technology: a new tool for the epidemiological typing of bacterial pathogens? FEMS Immunol Med Microbiol 2006, 47:178-189.

48. Monecke S, Jatzwauk L, Weber S, Slickers P, Ehricht R: DNA microarraybased genotyping of methicillin-resistant Staphylococcus aureus strains from Eastern Saxony. Clin Microbiol Infect 2008, 14:534-545. 
49. de Bruin A, de Groot A, de Heer L, Bok J, Wielinga PR, Hamans M, van Rotterdam BJ, Janse I: Detection of Coxiella burnetii in complex matrices by using multiplex quantitative $P C R$ during a major $Q$ fever outbreak in The Netherlands. Appl Environ Microbiol 2011, 77:6516-6523.

50. Ribosomal RNA Operon Copy Number Database. http://rrndb.umms.med. umich.edu/search.php.

51. Pang H, Winkler HH: Transcriptional analysis of the 16s rRNA gene in Rickettsia prowazekii. J Bacteriol 1996, 178:1750-1755.

52. Afseth G, Mallavia LP: Copy number of the $16 \mathrm{~S}$ rRNA gene in Coxiella burnetii. Eur J Epidemiol 1997, 13:729-731.

53. Bernasconi MV, Casati S, Péter O, Piffaretti JC: Rhipicephalus ticks infected with Rickettsia and Coxiella in Southern Switzerland (Canton Ticino). Infect Genet Evol 2002, 2:111-120.

54. Lee JH, Park HS, Jang WJ, Koh SE, Park TK, Kang SS, Kim BJ, Kook YH, Park $\mathrm{KH}$, Lee SH: Identification of the Coxiella sp detected from Haemaphysalis longicornis ticks in Korea. Micro Immun 2004, 48:125-130.

55. Mediannikov O, Ivanov L, Nishikawa M, Saito R, Sidelnikov YN, Zdanovskaya $\mathrm{NI}$, Tarasevich IV, Suzuki H: Molecular evidence of Coxiella-like microorganism harbored by Haemaphysalis concinnae ticks in the Russian Far East. Ann N Y Acad Sci 2003, 990:226-228.

56. Clay K, Klyachko O, Grindle N, Civitello D, Oleske D, Fuqua C: Microbial communities and interactions in the lone star tick, Amblyomma americanum. Mol Ecol 2008, 17:4371-4381.

57. Mattila JT, Burkhardt NY, Hutcheson HJ, Munderloh UG, Kurtti TJ: Isolation of cell lines and a rickettsial endosymbiont from the soft tick Carios capensis (Acari: Argasidae: Ornithodorinae). J Med Entomol 2007, 44:1091-1101.

58. Burgdorfer W, Hayes SF, Mavros AJ: Non-pathogenic rickettsiae in D. andersoni, a limiting factor for the distribution of Rickettsia rickettsii. In Rickettsiae and rickettsial diseases. Edited by Burgdorfer W, Anacker RL. New York: Academic Press, Inc; 1981:585-594.

59. Noda $H$, Munderloh UG, Kurti TJ: Endosymbionts of ticks and their relationship to Wolbachia spp. and tick-borne pathogens of humans and animals. Appl Environ Microbiol 1997, 63:3926-3932.

60. Scoles G: Phylogenetic analysis of the Francisella-like endosymbionts of Dermacentor ticks. J Med Entomol 2004, 41:277-286.

61. Sun LV, Scoles GA, Fish D, O'Neill SL: Francisella-like endosymbionts of ticks. J Invertebr Pathol 2000, 76:301-303.

62. Dale C, Moran NA: Molecular interactions between bacterial symbionts and their hosts. Cell 2006, 126:453-465.

63. Nakabachi A, Yamashita A, Toh H, Ishikawa H, Dunbar HE, Moran NA, Hattori M: The 160-kilobase genome of the bacterial endosymbiont Carsonella. Science 2006, 314:267.

64. Klyachko O, Stein BD, Grindle N, Clay K, Fuqua C: Localization and visualization of a Coxiella-type symbiont within the lone star tick, Amblyomma americanum. Appl Environ Microbiol 2007, 73:6584-6594.

65. Moran NA, Degnan PH, Santos SR, Dunbar HE, Ochman H: The players in a mutualistic symbiosis: insects, bacteria, viruses, and virulence genes. Proc Natl Acad Sci USA 2005, 102:16919-16926.

\section{Submit your next manuscript to BioMed Central and take full advantage of:}

- Convenient online submission

- Thorough peer review

- No space constraints or color figure charges

- Immediate publication on acceptance

- Inclusion in PubMed, CAS, Scopus and Google Scholar

- Research which is freely available for redistribution

Submit your manuscript at www.biomedcentral.com/submit
C Biomed Central 